\title{
BIOLOGIA DA AUTONOMIA: A IMPORTÂNCIA DA TEMPORALIDADE DE FREIRE E DO FENÔMENO HISTÓRICO DE MATURANA PARA O ENSINO DE BIOLOGIA
}

\author{
Herbert Gomes da Silva \\ Maria Elena Infante-Malachias \\ Universidade de São Paulo (USP), Ribeirão Preto, São Paulo, Brasil
}

\begin{abstract}
Resumo: O objetivo deste artigo é discutir a importância do fenômeno histórico e a temporalidade, relacionando-os à educação e aprendizagem. Utilizamos as teorias de Humberto Maturana e Paulo Freire, como princípios para a Biologia da Autonomia. Defendemos a ideia de uma educação e ensino de Biologia, voltados para a formação humana tendo o estudante como sujeito/ observador que interfere e age de maneira reflexiva e consciente no mundo em que vive. Para isso, é necessário que ele compreenda a sua importância como sujeito histórico e que a sua aprendizagem é um fenômeno observável a partir dessa concepção.

Palavras-Chave: Ensino de Biologia. Aprender. Historicidade. Fenômeno Histórico.
\end{abstract}

1. INTRODUÇÃO

Por meio deste artigo, explicitaremos alguns conceitos fundamentais sobre a condição biológica e social humana que originam a aprendizagem no ensino de Biologia, e ao mesmo tempo, buscamos a compreensão da história do indivíduo na educação por meio de uma epistemologia que valorize o desenvolvimento da autonomia dele. A esse corpus teórico, consciente da 
fundamental condição biológica do ser humano e pautados em algumas das ideias de Humberto Maturana, Francisco Varela e Paulo Freire, denominamos como Biologia da Autonomia.

Como princípio da Biologia da Autonomia, defendemos que um dos objetivos do ensino de Biologia é desenvolver autonomia na aprendizagem nos estudantes. Nesse sentido, entendemos que um ser humano é autônomo quando fundamentando em uma ética universal (FREIRE, p. 17, 1974) na qual, o conhecimento (MATURANA; VARELA, 2001b; VARELA, 1990) e as emoções permitam ações conscientes no seu modo de viver, respeitando sua condição biológica cognitiva, seja na individualidade - respeitando a si, seja na vida em sociedade - respeitando o outro em uma legítima convivência (MATURANA, 2001).

Temos como objetivo explicitar a importância dos conceitos da temporalidade (FREIRE, 1967, 1974) para a compreensão de elementos que compõem a vida dos seres humanos e que tem consequências no ensino de Biologia. Abordaremos conceitos relacionados à aprendizagem, oriundos dos fundamentos biológicos e sociais para as relações educacionais humanas utilizando como referência o fenômeno histórico (MATURANA;VARELA, 2001).

\section{Fundamentos PARA O ENSINO DE BIOLOGIA NA SOCIEDADE}

Somos seres biológicos e por isso possuímos um tipo específico de organização. Entendemos aqui o conceito de organização como o conjunto de relações entre elementos, sistemas e constituintes, que devem existir ou ocorrer e que atribuem identidade ao ser. O nosso tipo especial de organização é denominado de autopoiesis (MATURANA; VARELA, 1974).

Humberto Maturana e Francisco Varela nomearam a nossa organização biológica pelo termo autopoiesis, no sentido de indicar que somos sistemas fechados que se retroalimentam, onde o produto do sistema gera o próprio sistema. A manutenção da organização é um princípio vital para a existência do ser humano e o que lhe permite existir com uma identidade particular (MATURANA; VARELA, 1974). O que distingue essa identidade é uma fronteira entre a dinâmica interna do organismo e a dinâmica externa que é o meio. Em nossa organização autopoiética, podemos perceber ou não perturbações do meio, de acordo com a nossa estrutura biológica (a estrutura corresponde aos componentes e relações da organização autopoiética). Nessa relação, entre o organismo e o meio, a variação estrutural (plasticidade estrutural) também se expande para as relações estabelecidas no âmbito social.

Neste sentido, Freire (2011, p. 53) afirma: 
Gosto de ser gente porque, como tal, percebo afinal que a construção da minha presença sobre o mundo, que não se faz no isolamento, isenta da influência das forças sociais, que não se compreende fora da tensão entre o que herdo geneticamente e o que herdo social, cultural e historicamente, tem muito a ver comigo mesmo.

A partir da interação entre a dinâmica interna de um indivíduo e o meio, é que se origina a relação entre o biológico, o social e o cultural, e esta interação cria a identidade do ser humano, assim como o seu modo único de ação no mundo. Isso significa que, cada estudante possui de acordo com sua identidade uma relação distinta com o conhecimento da Biologia, e usa como referência primordial um fechamento em si, ou seja, a referência centrada em si.

Para compreender essa referência em si, devemos conhecer o funcionamento particular do sistema nervoso humano. Na organização autopoiética humana, o sistema nervoso possui os sistemas sensoriais visual, auditivo, tátil, gustativo, olfativo, vestibular e proprioceptivo - os quais permitem a percepção de perturbações oriundas no meio. Esses sistemas sensoriais integram a estrutura que interage e interfere na dinâmica interna em fechamento operacional do sistema nervoso em si. Humberto Maturana e Francisco Varela $(1974,2001)$ denominaram esse fechamento da dinâmica interna como Clausura Operacional, sendo esse o modo de operar do sistema nervoso que encerra em si a referência do seu funcionamento. Assim, toda experiência realizada pelo sistema nervoso é válida, já que o referencial de seu modo de operar é o próprio funcionamento dele, ou seja, sua dinâmica interna.

Maturana e Varela (2001, p. 149) afirmam que: "o sistema nervoso funciona com representações do mundo"; essa perspectiva considera que existe uma dinâmica interna funcionando em clausura operacional que constrói uma percepção particular do mundo pelos sujeitos, e neste caso, pelos estudantes. Essa condição biológica permite a existência de uma classe de fenômenos que determina a identidade do que é ser um humano e da identidade particular dos estudantes (utilizada como referência por ele em seu modo de se por diante do mundo). O professor quando ensina Biologia utiliza essa referência do que é ser humano e de sua identidade individual para construir modelos de representações dos fenômenos biológicos que nos rodeiam.

A organização autopoiética é a origem fundamental que faz surgir uma nova classe de fenômenos interpretativos (MATURANA; VARELA, 1974), que existirão e influenciarão a história particular da vida dos estudantes na referência em si mesmos. Essa distinção de interpretação é fundamental para entender as concepções de mundo e a diversidade do desenvolvimento 
cognitivo entre estudantes, o que justifica a variedade de representações do mundo, e que deve ser considerada para a aprendizagem de Biologia. Nessa perspectiva a respeito das concepções, Maturana e Varela (2001) reforçam a necessidade de tomar cuidado para não negar a existência de um meio circundante ao estudante, o que seria uma ação de isolamento referencial, mas também, ter o cuidado para não conceber o sistema nervoso como um receptor passivo de informações do meio externo, negando-lhe a criação, aprendizagem e interação. Nesse intuito, referenciando as concepções construídas pelos seres humanos, do qual a ciência faz parte (SILVA 2012), Maturana e Varela (2001) alertam: "Tudo que é dito é dito por alguém", dando ênfase à necessidade de conferir a autoria do indivíduo que diz, descreve, interpreta e concebe.

Considerando a variedade perceptiva neurobiológica, a herança cultural e a herança social defendida por Paulo Freire, há de existir uma diversidade de concepções sobre a Biologia, que deve ser vista como legítima para o desenvolvimento da autonomia dos estudantes. Isso deveria estar em constante evidência na sala de aula, pois, dessa variedade interpretativa podem surgir diferentes modos de interação e percepção. Cabe ao professor reconhecer a existência desses multiversos (MATURANA, 2001) em que a sala de aula é constituída e, para que a existência desses multiversos seja um elemento favorável à aprendizagem, deve-se compreendê-los como legítimos, e respeitá-los na dinâmica interacional entre estudantes e professores de Biologia. Freire (2011 p. 58) afirma: "O respeito à autonomia de cada um é um imperativo ético e não um favor que podemos ou não conceder uns aos outros".

A identidade de uma sociedade é construída pela sua cultura. As comunidades humanas interagem e constituem-se na linguagem, assim como o ser humano é constituído também na linguagem (MATURANA; VARELA, 2001). Se o que queremos é entender o ensino de Biologia, devemos buscar e compreender o que se conserva, e para que haja interação na sociedade ou no ensino, o principal fenômeno que se conserva é a linguagem. E a partir dela, conservam-se outros fenômenos como identidade, cultura, valores da humanidade, ciências, Biologia entre outros. A conservação da identidade de uma sociedade depende da linguagem, meio pelo qual ela interage entre si, e onde a Biologia deve ser integrada pelo ensino.

\section{Aprendizagem e RefleXão na temporalidade}

Aprender é mudar para um estado cognitivo presente diferente de um estado anterior, que surge ao longo de uma linha temporal por 
meio da experiência na vida de um indivíduo. Como fenômeno biológico é desencadeado tanto pela realização da dinâmica interna (clausura operacional), quanto pela experiência vivencial em relação com o meio em constante interação. A distinção da aprendizagem só é possível no domínio comportamental e em relação a uma referência histórica do indivíduo.

Do mesmo modo, a aprendizagem é uma mudança contínua na história de vida do ser humano, que não está restrita ao espaço escolar (ou espaço planejado). Sob essa concepção, aprendemos desde o início da divisão da célula-ovo, perpassando a maturação do sistema nervoso no processo de formação uterina, até o fim da nossa organização autopoiética, momento em que a vida tem seu fim.

Na visão Freireana, o ser humano existe e não apenas vive como os outros seres vivos, e a sua existência está circunscrita a duas dimensões onde ele é e se realiza: a natural e a cultural. A dimensão natural é a natureza biológica do homem, que neste texto abordamos a partir da Biologia do Conhecer de Maturana. Já na dimensão cultural da linguagem e da expressão, o homem se lança na invenção de si e do mundo, o homem interfere e cria. Nesta dupla inserção no mundo, o homem toma consciência de si e é capaz de sair do tempo e se projetar fora dele, emergindo para além do tempo. Nas palavras de Freire, o homem: "[...] não está preso a um tempo reduzido a um hoje permanente que o esmaga, emerge dele. Banha-se nele. Temporalizase" (FREIRE, 1967, p. 41). A perspectiva de temporalidade tem aqui uma importância fundamental, uma vez que o homem nesta condição pode-se tornar sujeito e agente da sua própria história. Assim, na temporalidade Freireana, o sujeito intervém na história e deixa marcas da sua passagem por ela, da mesma forma a temporalidade marca o sujeito, uma vez que:

O homem pode ser eminentemente interferidor. Sua ingerência, senão quando destorcida e acidentalmente, não lhe permite ser um simples espectador, a quem não fosse lícito interferir sobre a realidade para modificá-la. Herdando a experiência adquirida, criando e recriando, integrando-se às condições de seu contexto, respondendo a seus desafios, objetivando-se a si próprio, discernindo, transcendendo, lança-se o homem num domínio que lhe é exclusivo - o da História e o da Cultura (FREIRE, 1967, p. 41).

Se para Freire, o homem é um sujeito interferidor que emerge do tempo e pode transformar o mundo na sua temporalidade, isto significa que ele está em um contínuo processo de aprender do, no e com o mundo. Dessa forma, o processo de aprendizagem, dentro das perspectivas teóricas apresentadas sucintamente neste texto, gera a necessidade de uma profunda reflexão sobre a educação. 
O ensino intervém e provoca perturbações em um ser humano que está em desenvolvimento constante. Na educação escolar, a aprendizagem está centrada em sua maior parte na relação entre o indivíduo e o meio; sendo assim, haverá interação e percepção de perturbações que podem estar de acordo com os objetivos do professor. Para conseguir vislumbrar essa perspectiva contínua, a mesma deve estar em evidência para quem a observa, à perspectiva de um presente contínuo cambiante (MATURANA, 2001) que pode ser compreendido com o auxílio do conceito de temporalidade, na qual o ser humano pode se projetar e interferir na realidade. No processo de ensino de Biologia, tanto o professor quanto o estudante, vivem no presente, validado por meio do seu sistema cognitivo. Assim, qualquer experiência vivida por eles está alçada em uma realidade que existe, de fato, no operar do seu sistema nervoso. Além disso, uma das características principais da organização autopóiética é a existência de adaptação às condições do meio, influenciada pela perturbação em que esse organismo existe. Essa adaptação da autopoiesis permite ao sistema nervoso uma plasticidade que possibilita mudanças na sua estrutura, sem modificar a sua organização (plasticidade estrutural). Desse modo, o organismo está em permanente mudança sem perder a sua organização, e consequentemente, em uma constante aprendizagem, em um presente contínuo cambiante.

Tanto o professor quanto o estudante estão imersos na clausura operacional de seus sistemas nervosos, tornando o presente imediato uma realidade perfeitamente válida (constituída por percepções e concepções referenciadas na sua identidade), incluindo as suas ações como fundamento na maneira de viver. O que muda da perspectiva de um para o outro são as percepções das perturbações que se originam no meio, seja por condições de uma experiência vivenciada, seja na interação em comunicação com outras pessoas.

Nesse ponto, há uma consideração que deve ser levada em conta no ensino de biologia. Se toda experiência vivida pelo ser humano é válida, na clausura operacional do seu sistema nervoso, como ele, o sujeito, irá saber que errou no vivenciar de uma experiência? Para que isso ocorra é necessária uma interação que o perturbe e provoque uma reflexão (ou uma mudança de referencial) e lhe permita perceber que pode ter havido um erro.

Para que a autonomia na aprendizagem seja uma condição social/ educacional humana, a reflexão e aprendizagem devem ser compreendidas como uma característica ontogênica também. A ontogenia é a história de mudanças estruturais de uma unidade/ser, sem que essa perca sua organização/identidade (MATURANA;VARELA, 2001). Assim, os seres humanos 
possuem uma ontogenia, ou seja, passam por diversas mudanças físicas e cognitivas durante o decorrer da sua história de existência, sem, no entanto, perder a sua identidade individual como ser. A reflexão e a aprendizagem são fenômenos que possuem naturezas ontogênicas enquanto elementos que ocorrem nos indivíduos durante toda sua vida. No entanto, o ato de aprender pode ser desprovido do ato fundamental de refletir criticamente (o aprendizado apenas por memorização ilustra de maneira adequada essa condição), importante para compreender como se aprende.

O sujeito na temporalidade é único nas suas perspectivas do mundo, ele tem um histórico, tem fundamentos e raízes que o individualizam na reflexão. Dessa forma, o processo reflexivo age como uma catapulta para temporalizar o sujeito; no entanto, no processo educativo escolar não há indivíduos e sim turmas, salas e grupos massificados onde a aprendizagem mecânica, apenas por memorização, gera acomodação e impede a inserção transformadora na realidade. Freire alerta sobre isto dizendo: "Daí que a massificação implique no desenraizamento do homem. Na sua "destemporalização". Na sua acomodação. No seu ajustamento" (FREIRE, 1967, p. 42).

Em nossa perspectiva, aprender é um fenômeno que gera (na ontogenia do ser) mudanças cognitivas, emocionais e conceituais, a partir de uma consciência reflexiva - reflexão crítica (FREIRE, 2011) de si, que thes permitem novas significações, interações e movimentações no meio que o circunda, em seu estar no mundo. Desse modo, a aprendizagem é um contínuo do fenômeno em que as mudanças são vivenciadas ou reveladas no desenvolvimento da ontogenia de um indivíduo, e ainda, só é percebida em relação à história desse indivíduo, quando temos como referência um estado anterior ao surgimento da mudança. Por isso, anteriormente, afirmamos que aprender é um estado presente contínuo cambiante da história do ser humano, onde não cabe a acomodação nem o ajustamento denunciados por Freire.

Estamos em constante mudança estrutural, sem, no entanto, perder a nossa organização autopoiética. $O$ conjunto de mudanças estruturais (cognitivas, fisiológicas, anatômicas, entre outras) compõe em sua totalidade o Fenômeno Histórico. Um Fenômeno Histórico, conceito criado por Maturana e Varela (1974), é o contínuo na vida de um ser vivo, no qual ocorre um conjunto de mudanças de forma sucessiva ao longo do tempo. Dessa forma, a aprendizagem é o fenômeno que ocorre entre um estado do ser que surge como modificação de um estado prévio que constitui as suas representações sobre o mundo em que vive. 
Atribuímos à condição de autonomia na aprendizagem do ser humano quando a aprendizagem é consciente sobre o desenvolvimento do fenômeno histórico na temporalidade, provida de reflexão crítica, ou seja, uma aprendizagem reflexiva consciente. $\mathrm{O}$ ato reflexivo do ser, como elemento fundamental à autonomia, permite ainda como constituinte da aprendizagem a ressignificação do que foi aprendido. Isso se dá, porque a reflexão permite a possibilidade da recursividade ou retroalimentação na aprendizagem, interferindo sobre as concepções do mundo ou, como o sujeito se põe no mundo (FREIRE, 1979).

O fenômeno histórico na perspectiva biológica possui ainda três variantes: I. Passado: que é a referência do ser humano a sua experiência em estados anteriores ao presente; II. Presente: estado estrutural atual do ser vivo em sua organização autopoiética e III. Futuro: construção da clausura operacional para possíveis estados estruturais posteriores ao presente.

Para Freire (1967), a resposta implícita para a pergunta sobre o que é humano? É a inserção do homem na história e no tempo, onde através da linguagem ele pode escrever a sua biografia e deixar marcas, registros da sua intervenção no mundo. Diferente do tempo unidimensional dos outros animais, o ser humano, mergulha no tempo multidimensional e ao se dar conta da sua temporalidade se projeta e sai de si na reflexão, isto é: "atinge o ontem, reconhece o hoje e descobre o amanhã" (FREIRE, 1967, p. 40).

Na reflexão, o sujeito pode avaliar o passado, reconhecer criticamente os condicionantes do hoje e se projetar com esperança para o tempo que virá e que ainda não é. Este processo é fundamental para o desenvolvimento da autonomia do sujeito.

As variantes do fenômeno histórico na perspectiva biológica de Maturana e Varela (presente, passado e futuro) podem ser distinguidas por um observador e têm uma relação direta com a existência de condições que promovam a existência de fenômenos como "Erro" e "Ilusão" para o ensino de Biologia.

\section{ERro e ILUSÃo no Fenômeno Histórico}

Restringiremos a análise agora aos fenômenos distinguidos como "Erro" e "Ilusão" no domínio cognitivo da clausura operacional do sistema nervoso em relação ao ensino de Biologia. O fluxo temporal do passado, presente e futuro impacta a educação, principalmente em relação ao planejamento. Planejar requer uma organização de elementos no espaço de aprendizagem para que seja possível alcançar um objetivo. Pelo menos, seria o que a prática almeja, e, ainda, é o que lhe dá sentido. 
O professor ao planejar um curso ou aula de Biologia, ensinará com suas concepções e construirá, a partir dessas, as perspectivas de resultados esperados na aprendizagem dos estudantes. O professor carrega muitos princípios quando realiza o seu plano. Esses princípios variam desde valores pessoais até a concepção de ciências que foi construída ao longo de seu percurso formativo profissional.

O professor busca no decorrer da sua ação influenciar as concepções dos estudantes com suas explicações sobre os fenômenos da Biologia. Fourez (2008, p. 27) afirma:"Um docente sempre se coloca, de maneira ou outra, em relação ao seu desejo de influenciar os alunos (desejo de distinguir seu projeto querido)". Quando ele imagina fazer apenas uma tarefa educativa sem estar implicado, não só se engana, mas ensina praticamente um "modo de ser"em relação ao seu desejo ou objeto de estudo. Isso possui aspectos positivos e negativos. Positivo quando sua concepção é um convite à reflexão, negativo quando sua concepção é opressora e assume o papel de transferência de conhecimento, assim como na perspectiva da educação bancária (FREIRE, 1974).

Planejar a formação de um estudante para um momento futuro é uma tarefa árdua para o professor. Quando o professor reforça os seus princípios ao fazer seu planejamento, ele se põe no papel de responsável pela condução da formação humana para o futuro, ou seja, responsável pela construção do cidadão do futuro. Eis aqui o "nó górdio" da educação. Educar para formar um cidadão que não existe. Essa é uma tarefa tão complicada, quanto desatar o nó realizado por Górdio para atar o carro de bois a uma coluna no templo do deus grego Zeus. A alusão ao nó também tem outro significado, além da dificuldade de desatá-lo: este representa os princípios e certezas envolvidas no ato de planejar, e que na maioria das vezes, são difíceis de desfazer. Quando a educação está impregnada desse contexto de certezas, a formação carrega um viés autoritário, o de tornar o estudante o mais parecido com as expectativas no presente, referenciada nas concepções dos professores.

Maturana (2002, p. 29) afirma que:

O educar se constitui no processo em que a criança ou o adulto convive com o outro e, ao conviver com o outro, se transforma espontaneamente, de maneira que seu modo de viver se faz progressivamente mais congruente com o do outro no espaço de convivência.

Essa relação recíproca é construída em uma contínua interação, onde ambos os envolvidos vão se modificando, e constituindo o seu consenso relacional no espaço em que vivem (ou seja, entram em acoplamento 
estrutural). Ambos se influenciam e ao mesmo tempo, se modificam estruturalmente em acoplamento. Neste sentido Freire insiste em que o homem é um ser de relações e não apenas de contatos. "Ele, o homem, não apenas está no mundo, mas com o mundo. Estar com o mundo resulta de sua abertura à realidade, que o faz ser o ente de relações que é" (FREIRE, 1967, p. 39). Da mesma forma essa relação de intensa interação foi descrita por Freire (2011, p. 25) para o sentido da prática educativa: "Quem ensina aprende ao ensinar e quem aprende ensina ao aprender".

A relação entre quem aprende e quem ensina não é ingênua, há nela interesses, expectativas declaradas e ocultas. A espontaneidade do convívio na relação de ensinar e aprender sofre o assédio do poder (FOUREZ, 2008) sobre a relação entre professor e aluno. $O$ caráter do poder diante da possibilidade e da responsabilidade, do controle e da manipulação de um ser humano em desenvolvimento é uma ideia sutilmente sedutora.

A ilusão e o erro são observáveis nos fenômenos biológicos. A cognição humana possui uma dinâmica sistêmica que compõe uma totalidade (Sistemas sensoriais, Sistema Nervoso Central e Periférico, abrangendo toda a extensão do organismo) que interage consigo e com o meio externo: outras pessoas, ambiente, estímulos, perturbações, e qualquer variante que venha de fora do organismo e o perturbe e que seja percebido por ele. Essa dinâmica integrada realiza a vivência no tempo presente. Dificilmente um ser humano percebe um erro advindo de sua conduta no tempo presente (tempo imediato). E para compreender a inexistência desse tipo de erro no presente, devemos separar a ação classificada como "erro", da ação de observar e julgar o erro, eventos externos a ação.

A partir dessa separação, "ação de erro" e "observação do erro", depende da informação da história desse indivíduo (fenômeno histórico) para identificá-lo. Assim, é possível distinguir um estado anterior ao que o observador está, ou seja, a existência do passado antecedendo o presente, e a observação do erro.

Desse modo, quanto à distinção por um observador só é possível perceber um "erro" a partir de duas posturas reflexivas a respeito de uma mudança de estado no fenômeno histórico:

1. O observador se referencia em um estado anterior seu e percebe uma mudança em relação ao estado presente, que poderia ou não corresponder a sua condição atual; caso não correspondesse à expectativa dessa condição seria distinguido o "erro" (ação do ser reflexivo). 
2. Um observador externo vê as manifestações do fenômeno histórico e, por diretriz estabelece o "erro". O erro em ambos os casos só pode ser percebido no passado. Por isso nenhum ser erra no presente ou no momento de errar (ação do observador), o erro sempre é percebido em um momento posterior.

As duas condições que permitem a distinção de um erro somente acontecem quando se remetem a um estado no passado como referência a um estado presente. $E$ isso tem um efeito determinante na educação.

O passado é um estado anterior ao presente. Ambos são advindos de uma interação concreta na vida, quando os estudantes são aceitos como sujeitos históricos (FREIRE; 1967), e ainda, são gerados como fenômenos observáveis a partir da conjunção da tríade social, biológico e cultural (MATURANA; VARELA; 2001). Já o futuro pertence a um domínio diferente do passado e do presente.

O passado e o presente são marcados pela natureza experiencial da vida do ser (não confundir com experimental), ou seja, pela experiência do viver. Neles está bem delimitado o envolvimento do indivíduo com o meio e sua experiência sensorial. O futuro, enquanto projeção, é diferente, será gerado a partir da dinâmica da clausura operacional do sujeito em sua constituição biológica.

Ambos os domínios (passado, presente e futuro) estão interligados, mas envolvem características diferentes. A relação entre os domínios é tão importante que a condição do presente, onde não existe o "erro" é a que permite e fornece possibilidade à existência do futuro como expectativa do observador (relacionado inclusive com a sua formação de identidade), e que pode retroagir no presente. Isso acontece no ato de planejar. Esse ciclo merece especial atenção, pois cria o que podemos distinguir como "ilusão".

Não estamos afirmando que toda construção sobre o futuro é ou se tornará uma ilusão, pois o futuro também diz respeito à predição (como a probabilidade), mas, que o futuro retroagindo no passado, pode criar a ilusão. Assim, a projeção do futuro, como oriundo da dinâmica interna do indivíduo, permite que exista a "ilusão", fenômeno antagônico na linha histórica do erro, pois a ilusão como fenômeno do presente pode afetar o fenômeno histórico, construindo-se e reconstruindo o próprio fenômeno. Como exemplo, sobre essas considerações acerca do ciclo da ilusão, podemos citar quando existe um idealismo na valorização que alguns professores podem ter a respeito de sua experiência educacional enquanto estudantes como melhor do que o estado atual (que pode ser real parcialmente, mas que possui muitos elementos advindos do ciclo ilusório), formando assim uma representação 
ideal. Isso é categorizado por Freire como uma posição ingênua, pois em uma interpretação simples dos problemas o homem opta"pela tendência em julgar que o tempo melhor foi o tempo passado" (FREIRE; 1967, p. 60). Para Soares, esta interpretação simples e ingênua da realidade tem uma explicação:

O professor, no exercício de suas funções e a escola, no cumprimento de seu papel, encontram-se frequentemente dissociados e apartados da contemporaneidade, não por escolha consciente, mas por força das circunstâncias do cotidiano. No dia-a-dia, o professor se envolve irrefletidamente com múltiplas tarefas e com múltiplas funções. Esse envolvimento, por vezes, obscurece aquela que deveria ser a sua maior característica, o exercício do livre pensamento. (SOARES, 2012 p. 842)

A ilusão no passado tem como referência o presente, e retroage sobre o ideal de como seria um estado melhor, já a ilusão do futuro projeta o idealismo do presente a um estado que ainda não existe. Ambas as condições remetem a uma ilusão, a um processo de alienação, e uma ação alienada corresponde àquela em que o sujeito mostra-se alheio e estranho ao processo e aos resultados da atividade desenvolvida (SOARES, 2012, p.850)

Nessa condição, a ilusão do ponto de vista biológico tanto no passado, quanto no futuro é totalmente válida, pois nosso organismo legitima sua experiência no presente, apesar de sofrer perturbações de ambos os extremos temporais: fenômenos históricos ou construções da dinâmica da clausura operacional a respeito do futuro.

Os domínios do "erro" e da "ilusão" nunca se sobrepõem, pois são fenômenos que se originam em domínios diferentes (erro = referência do passado e ilusão = referência no presente e para o futuro). Por outro lado, mesmo sendo originada em domínios diferentes, a "ilusão" pode resultar em "erro", e o "erro" pode contribuir para que surja a "ilusão", ambos constituem um continuum em relação a uma linha de manifestações no fenômeno histórico de um ser vivo. Nossa constituição biológica possibilita a existência da linguagem, que fundamenta a reflexão, meio pelo qual o "erro" pode ser percebido pelo sujeito agente ou pelo observador externo. O mesmo aplicase para a "ilusão".

O "erro" pode ser identificado por um observador externo, o que já constitui um fenômeno social, pois para que ele seja externo ao fenômeno histórico de um indivíduo, ele deve compartilhar uma coexistência mínima com esse ser observado. Já a "Ilusão" só pode ser identificada na relação social reflexiva.

O planejamento educacional não foge a esses princípios. O planejamento por um lado é uma ação que ocorre no presente, abrindo e 
gerando o futuro como perspectiva (que pode gerar "ilusão"). Por outro lado, refletindo sobre o "erro" o professor também gera uma perspectiva futura, no entanto consciente de suas características.

Os professores geralmente são formados para o futuro. $O$ estudante é um estado anterior do que se espera dele no futuro. A instituição escolar planeja para o futuro também. Todo esse contexto é válido, pois essas ações foram concebidas no presente. É uma operação legítima dos indivíduos que as fizeram, pois vivem em um contínuo presente em sua clausura operacional.

A nossa proposta de Biologia da Autonomia atualiza e incorpora os conceitos de temporalidade e de fenômeno histórico na formação dos sujeitos: estudantes e/ou professores. Para o estudante, a influência do fenômeno histórico (incluindo nele a dinâmica entre passado, presente e futuro, erro e ilusão) é a consciência da temporalidade são fundamentais para compreender e acompanhar a sua aprendizagem. Para o professor, a compreensão destes conceitos situa-o como um intelectual que ciente da sua responsabilidade na formação humana dos estudantes, assume a liderança para ajudar a desvelar certezas e ideologias através da reflexão. A observação e a compreensão da sua linha temporal o tornam o sujeito que intervém no seu modo consciente de aprender. Desse modo, a educação escolar pode ser integradora e cumprir seu papel de contribuir com o desenvolvimento da autonomia do sujeito que se põe no mundo e como parte dele.

\section{Considerações Finals}

Conceber a ideia de um ensino de Biologia voltado para cidadãos do futuro a partir de uma reflexão é deslocar o ser de um tempo para o outro sem considerar o fenômeno histórico e assumir um posicionamento autoritário sobre outro ser. É tornar o estudante um objeto e não sujeito (FREIRE, 1967, 2011).

Pensar em um ensino fundamentado na previsão de um perfil de ser humano que ainda não existe, é uma prática habitual nas escolas brasileiras. Há uma natureza descabida na ação do professor de Biologia em planejar e agir em um ensino no presente, para um futuro ser humano do qual não há previsibilidade de resultado concreto.

Talvez essa modalidade de ensino seja marcada pela perspectiva epistemológica das Ciências em querer prever os fenômenos naturais (o mesmo pensamento matriz que segue a formação do pensamento científico poderia ser ao mesmo tempo, o fundamento que sustenta essa concepção de ensino de Ciências); a completa ignorância de quem é o sujeito que está sendo formado e quem é esse ser humano. Pode-se dizer ainda, o professor 
de Biologia projeta seu perfil acadêmico (e social) sobre seus estudantes, ou seja, sua representação sobre o mundo em que vive.

Como uma contraproposta antagônica a um ensino científico voltado para o futuro, é possível uma perspectiva de ensino no presente, voltado para a formação de um ser humano, com base no contexto no tempo real do desenvolvimento biológico e social, essa é a proposta que defendemos neste texto: a perspectiva da biologia da autonomia. Se de um lado no ensino para o futuro temos como objetivo um cidadão inexistente, na perspectiva do ensino para o presente, não temos cidadão algum. O que temos é um ser biológico e social, ser humano, estudante, com sua sensorialidade idiossincrática, em pleno desenvolvimento, que não corresponde ao "ilusório" ser construído que é o objetivo do ensino, mas sim um sujeito único se posicionando sobre o mundo enquanto observador (MATURANA; VARELA, 2001), e enquanto sujeito histórico (FREIRE, 1967) no tempo presente contínuo cambiante. A temporalidade como a condição do ser humano que lhe possibilita sair e se projetar em um tempo multidimensional onde pode analisar o passado, vivenciar e experienciar o presente e se projetar para o futuro, lhe permitem a tomada de consciência que precisa para se tornar um sujeito autônomo e solidário.

O professor vive na certeza de sua formação, e para o ensino no presente, no entanto, deverá deixar e/ou afrouxar suas amarras, lidando com o"erro" e a "ilusão", cedendo espaço a muitas possibilidades no presente e à imprevisibilidade no futuro. Olhar para o ensino do presente é soltar as amarras da certeza e viver mergulhado em um espaço que pode gerar múltiplos universos existenciais, permitindo o surgimento de uma autonomia máxima social. Isso exige um desprendimento das estruturas de valores e dos moldes sociais em que o professor de Biologia foi formado e se desenvolveu para o ato de ensinar (desde a escola básica até a sua formação universitária).

Diante de uma perspectiva tão aterradora quanto à incerteza do futuro é normal que um planejamento para o ensino pareça algo desprovido de sentido. Mas isso é um cadafalso para o ensino de Biologia voltar à perspectiva de educar para formar seres humanos no futuro. É possível e necessário o planejamento do ensino - devemos planejar para o desenvolvimento do ser humano em sua formação individual-social e biológica, no presente, para que ele venha a ser no futuro um ser humano com autonomia em sua legitimidade, de acordo com sua própria história. Isto é, em muitas vezes, o contrário daquilo que os "adultos" do presente desejariam que esse ser humano fosse. 
As relações humanas não são apenas contatos, o ser humano não vive apenas, ele existe interferindo e modificando a realidade (FREIRE, 1967, 1974):

O conceito de relações, da esfera puramente humana, guarda em si, como veremos, conotações de pluralidade, de transcendência, de criticidade, de consequência e de temporalidade. As relações que o homem trava no mundo com o mundo (pessoais, impessoais, corpóreas e incorpóreas) apresentam uma ordem tal de características que as distinguem totalmente dos puros contatos, típicos da outra esfera animal. Entendemos que, para o homem, o mundo é uma realidade objetiva, independente dele, possível de ser conhecida. É fundamental, contudo, partirmos de que o homem, ser de relações e não só de contatos, não apenas está no mundo, mas com o mundo. Estar com o mundo resulta de sua abertura à realidade, que o faz ser o ente de relações que é (FREIRE, 1967, p. 19).

Neste texto, discutimos a Biologia da Autonomia a partir de Freire, Maturana e Varela, como a condição de autonomia na aprendizagem do ser humano quando este é consciente do seu desenvolvimento em um processo denominado fenômeno histórico na sua temporalidade. A reflexão crítica é a marca deste sujeito estudante, e a sua aprendizagem é reflexiva e consciente. Insistimos no que foi exposto anteriormente neste texto, o ato reflexivo do ser, é o elemento fundamental da sua autonomia e justificada na sua constituição biológica. A reflexão permite a possibilidade da recursividade ou retroalimentação na aprendizagem, interferindo sobre as concepções do mundo ou, na forma como o sujeito se põe no mundo (FREIRE, 1979).

Sendo assim, o que podemos contribuir enquanto educadores para o futuro? A legitimidade do ser no tempo presente, no hoje. O ser que tem um desenvolvimento de acordo com sua forma particular, realizando-se enquanto cidadão, provido de conhecimentos que revelam sua historicidade e seu modo de agir socialmente inserido em uma realidade cultural e biológica. As ideias expressadas aqui, se bem foram escritas pensando no professor e para o ensino de Biologia, são uma necessidade urgente para qualquer ser humano que trabalhe na formação do outros seres humanos. Com a Biologia da Autonomia propomos que a educação contribua na formação do ser humano em sua legitimidade, é isso que devemos esperar para o futuro que ainda não existe. 
BIOLOGY OF AUTONOMY: THE IMPORTANCE OF FREIRE'S TEMPORALITY AND MATURANA'S HISTORICAL PHENOMENON FOR BIOLOGY EDUCATION

ABSTRACT: The purpose of this article is to discuss the importance of the historical phenomenon and historicity, linking them to education and learning. We used the theories of Humberto Maturana and Paulo Freire, as principles for Biology of Autonomy. We are defending the need for education, within biology teaching, focused on human development where the student is both the subject/ observer who interferes and acts in reflective and conscious way in the world he lives, and because of it, he understands its own importance as an historical subject. Therefore his learning is an observable phenomenon within that design.

KEYWORDs: Autonomy of Biology. Biology Teaching. Learning. Historicity and Historical Phenomenon.

BIOLOGÍA DE LA AUTONOMÍA: LA IMPORTANCIA DE LA TEMPORALIDAD DE FREIRE Y DEL FENÓMENO HISTÓRICO DE MATURANA PARA LA ENSEÑANZA DE BIOLOGÍA

RESUMEN: El objetivo de este artículo es discutir la importancia del fenómeno histórico y la temporalidad, relacionándolos a la educación y al aprendizaje. Hemos utilizado las teorías de Humberto Maturana y Paulo Freire, como principios para la Biología de la Autonomía. Defendemos la idea de una educación y enseñanza de Biología, centradas en la formación humana, considerando al estudiante como sujeto/observador que interfiere y actúa de forma reflexiva y consciente en el mundo en que vive. Para ello es necesario que él comprenda su importancia como sujeto histórico y que su aprendizaje es un fenómeno observable a partir de ese diseño.

Palabras clave: Enseñanza de Biología. Aprendizaje. Historicidad. Fenómeno Histórico.

\section{REFERÊNCIAS}

FOUREZ, G. Educar: docentes, alunos, escolas, éticas, sociedades. São Paulo: Ideias e Letras, 2008.

FREIRE, P. Educação como prática de liberdade. Rio de Janeiro: Paz e Terra, 1967. Pedagogia do oprimido. Porto: afrontamento, 1974.

Conscientização: teoria e prática da libertação. Introdução ao pensamento de Paulo Freire. São Paulo: Cortez Editora, 1979.

Pedagogia da autonomia. Rio de Janeiro: Paz e Terra, 2011.

MATURANA, H. Cognição, ciência e vida cotidiana. Belo Horizonte: Editora UFMG, 2001. . Emoções e Linguagem em Educação e Política. Belo Horizonte: Editora UFMG, 2002. 
;VARELA, F. De maquinas y seres vivos - autopoiesis: La organización de lo vivo. Santiago: Editora Universitária, 1974.

; VARELA, F. A árvore do conhecimento: as bases biológicas da compreensão humana. 8. ed. São Paulo: Palas Athenas, 2001.

SILVA, H. G. O Explicar: a explicação humana na perspectiva do observador como ser biológico e cultural. 2012. 143 f. Dissertação. (Mestrado em Ciências - Ensino de Biologia) - Instituto de Biociências, Instituto de Física, Instituto de Química e Faculdade de Educação da Universidade de São Paulo. São Paulo, SP, 2012.

SOARES, A. S. A autoridade do professor e a função da escola. Educ. Real, Porto Alegre, v. 37, n. 3, p. 841-861, set./dez. 2012.

VARELA, F. Conocer. Barcelona: Editora Gedisa, 1990.

Herbert Gomes da Silva: Doutorando em Educação (Ensino de Ciências) pela Universidade de São Paulo (USP). Mestre em Ciências (Ensino de Biologia) pela mesma instituição. Atua na área de Ensino de Ciências Naturais e Ciências Biológicas, Pesquisa Ensino, Filosofia e História da Ciência, Neurociências, Cognição e a Biologia Cultural de Humberto Maturana e Francisco Varela. Pesquisador e Subcoordenador do Grupo de Pesquisa em Ensino de Ciências e Biologia do Conhecer (GPEnCiBiC) da Universidade de São Paulo. Especialista da Secretaria do Estado da Educação de São Paulo em políticas públicas e currículo da área de Ciências da Natureza.

E-mail: pesquisahgs@smail.com

Maria Elena Infante-Malachias: Doutora em Genética e Biologia Molecular (Ciências) pela Universidade Estadual de Campinas (Unicamp). Foi docente durante 10 anos na Escola de Artes, Ciências e Humanidades da Universidade de São Paulo junto ao curso de Licenciatura em Ciências da Natureza. Atualmente é professora Livre Docente MS-3 em RDIDP junto ao Departamento de Educação, Informação e Comunicação da Faculdade de Filosofia, Ciências e Letras (FFCLRP) da Universidade de São Paulo em Ribeirão Preto. Orientadora plena vinculada ao Programa de Pós-Graduação Interunidades em Ensino de Ciências da USP desde 2007 e ao Programa de Pós Graduação da FEUSP. Coordena o Grupo de Pesquisa em Ensino de Ciências e Biologia do Conhecimento ( $\mathrm{GPEnCiBiC}$ ) que conta com a participação de alunos de Iniciação Científica e de Pós-Graduação.

E-mail:marilen@usp.br 